\title{
Energy Reference Forecast and Energy Policy Targets for Germany
}
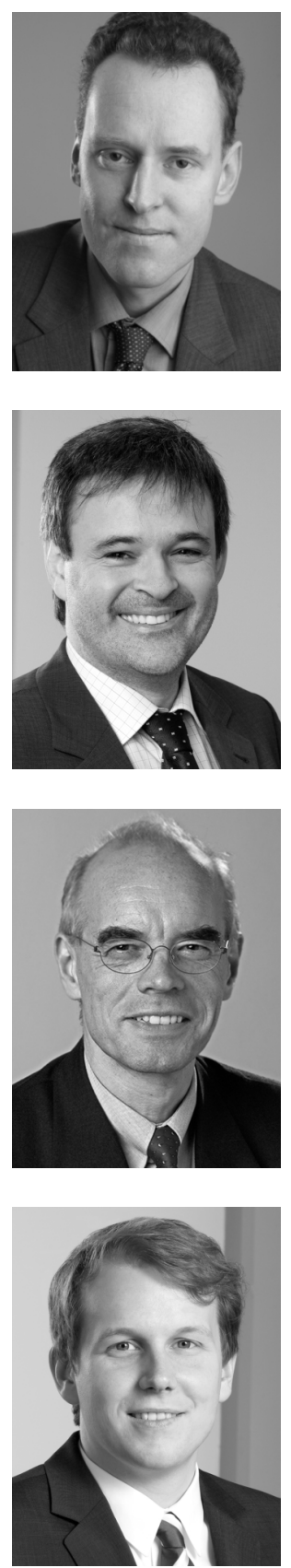

Christian Lutz, Dietmar Lindenberger, Michael Schlesinger and Christian Tode

Energy Forecast, Scenario, Energy Policy Targets, Energy Markets, Models

Energieprognose, Szenario, energiepolitische Ziele, Energiemärkte, Modelle

The core of the project "Development of Energy Markets - Energy Reference Forecast" is a conditional forecast of probable energy industry development up to the year 2030, complemented by a Trend Scenario extending to the year 2050. In addition, a Target Scenario and sensitivity calculations are presented, along with several discussions surrounding a number of focal point topics.

In the Reference Forecast and Trend Scenario, the goals of the German government's Energy Concept will, for the most part, not be achieved. The Target Scenario shows what would be required in order to attain the energy and climate protection objectives defined in the Energy Concept.

Kern des Projekts „Entwicklung der Energiemärkte - Energiereferenzprognose" stellt die bedingte Prognose der wahrscheinlichen energiewirtschaftlichen Entwicklung bis zum Jahr 2030 dar, ergänzt um ein bis ins Jahr 2050 reichendes Trendszenario. Daneben wurden u.a. ein Zielszenario und Sensitivitätsrechnungen erstellt sowie mehrere Schwerpunktthemen behandelt.

In Referenzprognose und Trendszenario werden die Ziele des Energiekonzepts der Bundesregierung überwiegend verfehlt. Das Zielszenario zeigt, was erforderlich wäre, um die im deutschen Energiekonzept definierten energie- und klimaschutzpolitischen Ziele zu erreichen.

\section{Background}

At the end of 2012 the German Ministry of Economy and Technology commissioned a study on the future development of energy markets in the light of the German Energy Concept and global developments. The main pillars of German Energy Concept from 2010, which has been adjusted after the Fukushima disaster in March 2011, is nuclear phase-out until 2022, a long-term shift to- 
wards renewable energy sources and reduction of greenhouse gas emissions (GHG) until 2050 of at least $80 \%$ against 1990 . This paper summarizes major results of the study (Prognos et al. 2014).

A look back reveals that global energy consumption has expanded by $50 \%$ since 1990 . The significance of fossil fuels remained unchanged up to 2011. Renewables became slightly more important, while the status of nuclear energy dropped somewhat. Energy-related $\mathrm{CO}_{2}$ emissions rose in tandem with primary energy consumption. Around $90 \%$ of this growth between 1990 and 2011 was accounted for by today's developing and emerging economies.

In Germany primary energy consumption and economic output became increasingly decoupled during 1990 and 2011. In the energy mix, fossil fuels have lost shares while renewables have captured them. Falling energy consumption and structural changes in favor of low or non-carbon energy sources led to a $24 \%$ drop in energy-related $\mathrm{CO}_{2}$ emissions between 1990 and 2011.

The core of the project "Development of Energy Markets - Energy Reference Forecast" is a forecast of probable energy industry development up to the year 2030, complemented by a Trend Scenario extending to the year 2050. In addition, a Target Scenario and sensitivity calculations are presented, along with several discussions surrounding a number of focal point topics.

The Reference Forecast provides a comprehensive look forward. From the view of the authors, it presents probable future energy industry developments as well as considers further stringent energy and climate protection policies and existing barriers to their implementation.

\section{Methodology}

The study uses a set of complex models that has been applied in earlier studies including the scenarios for the German Energy Concept (Prognos et al. 2010). Due to the complexity of and the differences between markets, electricity markets, final energy demand and macroeconomic implications of changes in energy prices and investment decisions are described in different models, which are soft-linked.

The Forecast and Target Scenario have been implemented in bottom-up models for the electricity sector in an EU electricity market optimization model (Nagl et al. 2011) and for final energy demand in sector specific models (Prognos/EWI/GWS 2010). They calculated energy volumes and prices and related cost resp. investment differences between the scenarios and the reference on a microeconomic basis (Lindenberger et al. 2010). These primary impulses are introduced into the macroeconomic model PANTA RHEI, in which they induce different second-round effects and reactions.

The energy demands in the scenarios are calculated with bottom-up simulation models. In those models energy-consuming appliances are mapped in high resolution by sector, application (e.g. domestic heating, mechanical energy, process energy, transportation...) and energy carrier in cohort methodology by age. Specific energy demands change with investment cycles, technological evolution, and political instruments or overall political framework (national and/or international). The mapped application cohorts (e.g. heated domestic space by building type, age, heating systems, or cohorts of vehicle types) evolve dynamically in dependence of the socio-economic framework. This type of modeling allows a very detailed mapping of the dependencies of different market segments and political in- 
struments as well as the inertia of developing processes due to long-lived investment goods (like buildings, vehicles, and power plants).

Detailed modelling of different energy markets is essential for such holistic analyses. In order to understand fuel price developments for globally traded energy commodities, such as natural gas and coal, two long-run partial equilibrium models were used for this study: COLUMBUS allows simulation of different evolutions of the global natural gas market until 2030 taking into account global interdependencies. In a similar fashion the TIMCO model simulates the global steam coal market and thus, allows to evaluate different global supply and demand developments. Given the internal energy market in the European Union, the German electricity system may not be modelled in an isolated fashion. Therefore, the DIMENSION model was extensively used for the study. DIMENSION is a longterm simulation model for the European electricity markets and simulates how the installed capacities of power plants and power storage facilities will develop in Europe in the future Richter (2011).

The economy-energy-environment model PANTA RHEI (Lehr et al. 2011; Meyer et al. 2012 ) is an environmentally extended version of the econometric simulation and forecasting model INFORGE (Ablert et al. 2009). The behavioral equations reflect bounded rationality rather than optimizing behavior of agents. All parameters are estimated econometrically from time series data. A detailed description of the economic part of the model is presented in Maier et al. (2014). For a description of the whole model see Lutz (2012).

The model results presented in section 3 depend on a number of assumptions and model specifics. Future behavior of economic agents is generally unknown and depending on circumstances. This is a drawback of future projections and scenarios. Results have to be interpreted keeping the difference between scenarios and projections in mind. Projections such as the Reference Forecast are linked to certain conditions. They show consistent and probable developments under these conditions. The aim of scenarios is to reveal impacts of developments or policy options.

To address at least some of these uncertainties five sensitivity calculations are used to test how differing prices for fossil fuels, alternate assumptions about cost developments of renewable energy technologies, and higher $\mathrm{CO}_{2}$ prices would affect key results. Only the sensitivity of higher $\mathrm{CO}_{2}$ prices shows a significant reduction of emissions after 2030. All other effects are small.

\section{Key Results}

In the base data the Reference Forecast and Trend Scenario assume the advancing integration of the global economy during the observation period 2011-2050. Economic weight will increasingly shift to today's emerging economies, especially those in Asia, during this period.

The German economy will grow in the medium and long terms at $1 \%$ p.a. Growth will be curbed by the country's falling population and the related decline in the labor force. Manufacturing will continue to maintain its key role for the German economy in the long term.

In international markets for crude oil, natural gas, and steam coal, price increases in real terms are expected for current market prices, which will be affected to a significant degree by increasing energy demand in Asian economies. Retail prices for petroleum prod- 
ucts, natural gas, and coal will be essentially determined by global market prices and exchange rates, as well as by taxes and fees.

Up until 2020, prices for $\mathrm{CO}_{2}$ certificates will remain at a moderate level due to, among other things, surplus allowances as a consequence of the economic and financial crisis. Recent measures regarding back-loading will have only a limited impact in this regard. A rise in $\mathrm{CO}_{2}$ prices after 2020 will result from the scarcity of certificates at the European level and, at the same time, will be dampened by the linkage of European climate protection efforts with those at the international level.

The individual national electrical power markets within Europe will continue to merge together. Grid expansion will play a central role and will continue to advance due to the changes in the institutional framework in Germany. The expansion of renewable energy use will also be increasingly organized in a cross-border manner after 2020 .

Residential, commercial, and industrial users in Germany will see a rise in retail prices in real terms up to 2025. For electricity intensive industries the cost of electricity will fall up to 2020 and then will begin to exhibit a steady increase.

Primary energy consumption (PEC) will decline throughout the observation period (Figure 1). With economic output increasing, this leads to greatly improved primary energy productivity. Renewables will claim a consistently fast-growing share of the energy supply. Wind and photovoltaic power will also boast high growth rates in the future. Biomass remains the most important renewable energy resource in the long term. More than half of all renewables will be used for generating electricity. Fossil fuels, however, will continue to make up the long-term basis of the country's energy supply.

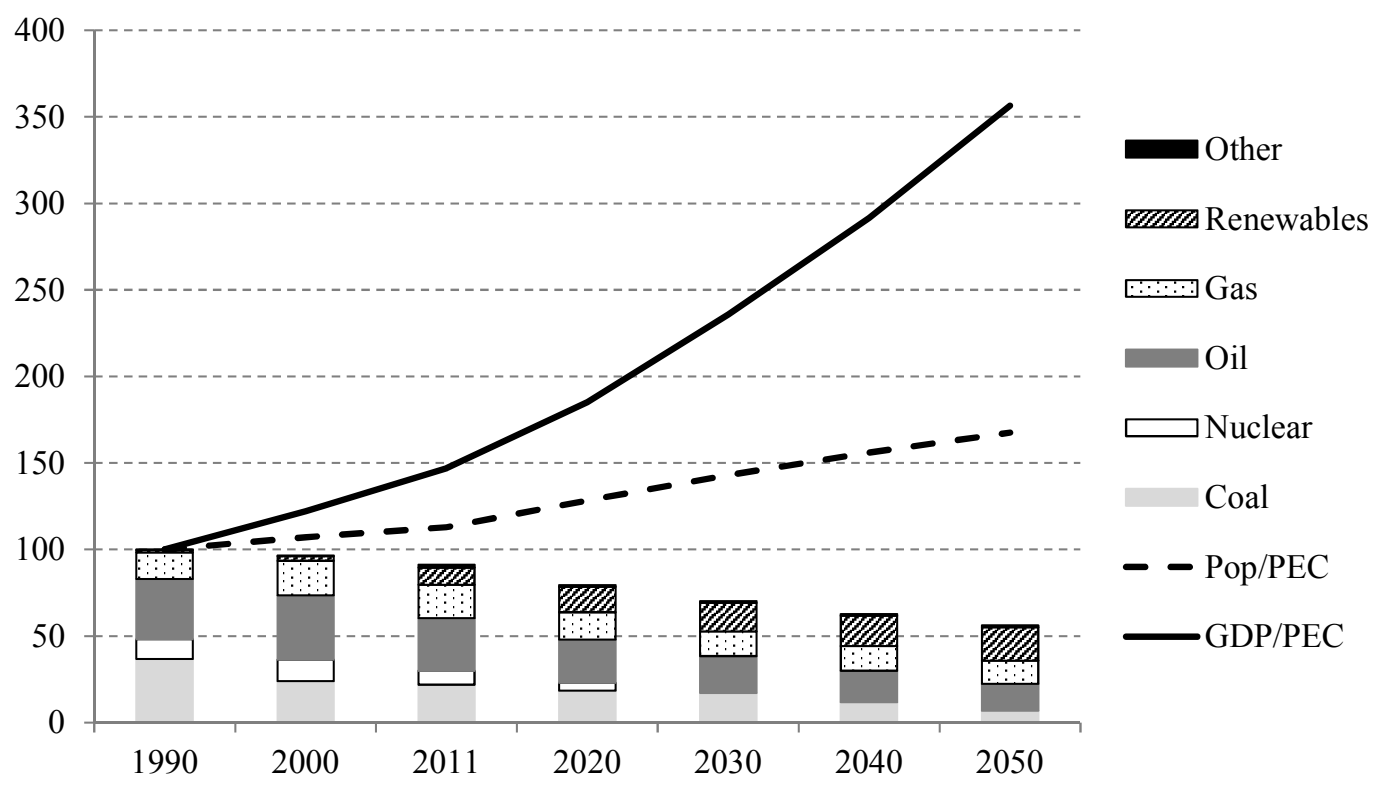

Figure 1: Primary energy consumption by energy source, primary energy productivity, and population/PEC in the Reference Forecast and Trend Scenario 1990 - 2050, Index: $1990=100$ 
Energy-related GHG emissions in 2020 will be $36 \%$ lower than in the Kyoto base year 1990 and $65 \%$ lower in 2050 due to the declining primary energy consumption and the associated GHG intensity, which falls over the long term. The energy sector and final consumers will contribute more or less equally to reducing emissions.

In the medium and long terms, final energy consumption will fall in all consumption areas (Figure 2). Final energy productivity will rise by just under $2 \%$ p.a. Fossil-based energy sources will see a drop in importance, while the share of renewables will climb significantly. Electricity will become the most important carrier of the energy mix by 2050 .

Energy consumption will fall in manufacturing even as output rises, indicating significant increases in energy productivity. Electricity will gain further importance as a power source for industrial users.

With increasing amounts of dwelling space and a rising number of private households, residential energy consumption will nonetheless drop sharply in the medium and long terms. This will be brought about by more energy-efficient buildings and appliances. The share of fossil fuels in the residential sector's energy mix will fall.

The heterogeneous commercial sector will experience a substantial drop in energy consumption, including the more dynamically growing branches. While consumption for space heating will drop sharply, use for cooling, ventilation, and building automation will see a massive increase.

Overall, energy consumption for transportation will fall during the observation period. This is primarily the result of increasingly fuel-efficient automobiles and trucks. The expansion of electro mobility will also contribute to this development. Gasoline and diesel will lose importance in favor of biofuels, electricity, and natural gas.

The national market areas for electrical power in Europe will continue to become more tightly linked. Grid expansion will play a central role, which will progress due to the changes in the institutional framework in Germany. The expansion of renewable energy use will likewise increasingly be organized in a cross-border manner after 2020.

The installed generation capacity of German power plants continuously rises during the observation period. This is primarily due to the major expansion of renewable energies and their relatively minor contribution to the secure power supply.

Electricity generation from coal-fired power plants will remain stable up to 2030 before dropping significantly. Operating hours of gas-fired power plants will decrease up until 2025 , primarily due to increasing generation from renewable energy. In the long term high $\mathrm{CO}_{2}$ certificate prices will account for growing shares of natural gas in electricity generation.

Over the course of the entire observation period electricity generation from renewable energy resources will increase significantly. After 2030, wind energy will account for the largest share of German electricity generation. With increasing cross-border cooperation, synergies will be exploited and promotion costs lowered.

Renewable energy technologies are in an early stage of development compared to conventional power sources. Due to learning effects and economies of scale, further cost decreases are expected in the coming years, especially regarding wind power and photovoltaic installations. Investment costs for conventional power plant technologies will remain stable over the next number of years. The focus of future developments will be on optimizing part-load behavior. 


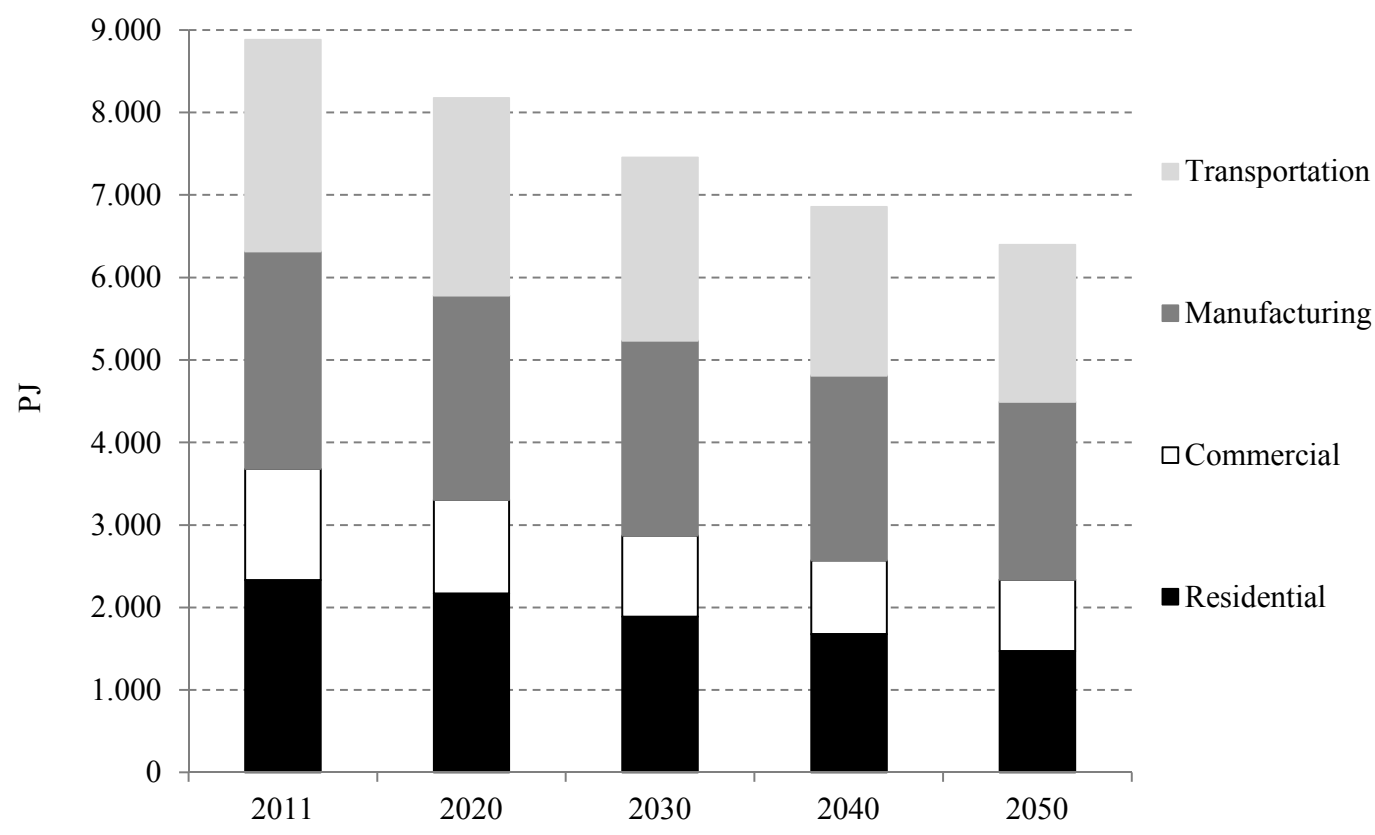

Figure 2: Final energy consumption by sector in the Reference Forecast and Trend Scenario 2011-2050, in PJ

Gross electricity generation from combined heat and power (CHP) plants will grow up to 2040. Due to a variety of conflicting goals, however, its expansion will fall considerably short of energy policy goals.

In the Reference Forecast and Trend Scenario, the goals of the German government's Energy Concept will, for the most part, not be achieved (see Figure 3 for GHG emissions). The Target Scenario shows what would be required in order to attain the energy and climate protection objectives defined in the Energy Concept.

Beyond developments outlined in the already ambitious Reference Forecast and Trend Scenario, attaining the targets will call for additional measures for reducing energy consumption and greenhouse gas emissions which are not cost-effective in all cases. In the area of final energy consumption, for example, more buildings must be renovated to be more energy efficient, savings potential in businesses must be further exploited, and greater efforts must be made to promote electro mobility. Different studies show that various barriers prevent private households and companies from investment in economic energy efficiency investment. Barriers include priority of other investment opportunities, uncertainty, short time horizons, fragmentation and market failures (see IEA 2012, 280 for an overview). 


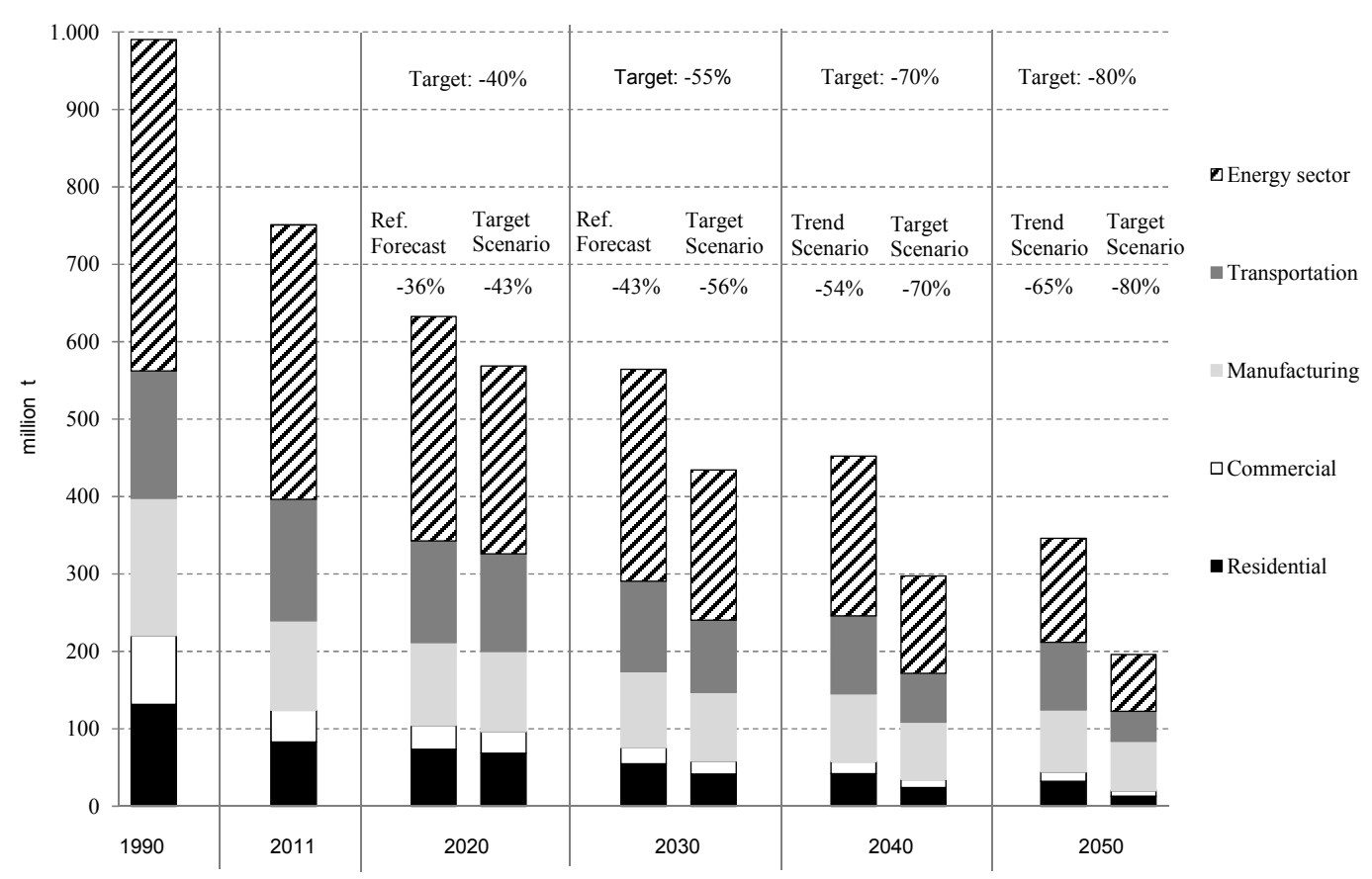

Figure 3: Energy-related GHG emissions in the Reference Forecast / Trend Scenario and Target Scenario $1990-2050$, in million t $\mathrm{CO}_{2}$ equivalents

Other preconditions are used in the Target Scenario than those in the Reference Forecast and Trend Scenario. It assumes that the energy and climate protection goals will be pursued as top priorities, and that political solutions are found to overcome the barriers which exist in many areas. The authors do not regard this as probable.

In order to reach the nation's energy policy goals regarding the decrease in GHG emissions, it is critical that generation from $\mathrm{CO}_{2}$ intensive power plants be reduced further. Due to both the integration of the German electricity market into the European network and the fact that the main control instrument for limiting emissions, the EU Emissions Trading System (ETS), is a European market, an effective climate protection policy can be implemented only to a limited extent at the national level.

The implementation of the Target Scenario in place of the Reference Forecast / Trend Scenario is connected with overall economic effects. In the medium term the implementation of the Target Scenario could be handled economically; in the longer term, it would have rather favorable effects.

\section{Comparison to other studies and outlook}

For assess the results within a broader analytical context, the Reference Forecast and Trend Scenario as well as the Target Scenario were compared with similar studies conducted by third parties. Shown from this is that the Energy Reference Forecast and the Energy Outlook 2012 (ExxonMobil 2012) are similar with regard to developments of primary energy productivity. The share of renewable is higher in the Reference Forecast than in 
the Outlook 2012 Forecast. The Target Scenario presented here and the comparable target scenario of the BMU (2012) study exhibit a similar drop in primary energy consumption. Energy-related $\mathrm{CO}_{2}$ emissions are reduced more quickly in the BMU target scenario due to faster expansion of renewable energy resources it foresees than in the report's Target Scenario.

Comparisons with other reference scenarios such as European Commission (2013) or UBA (2013) are difficult as they assume no further policies beyond those already implemented in a base year. The focus of these studies is on needs for and impacts of additional measures to reach certain targets. Other studies such as SRU (2012) are target scenarios, which just look at technical feasibility of high shares of renewable energy. Due to varying characteristics and assumptions, a comparison with the other studies therefore provides only conditionally meaningful results.

An essential prerequisite for reaching the energy and climate protection targets is efficient energy use. The increase in energy efficiency often requires investment in energy-saving technologies. New and further developed technologies for the use and conversion of energy are the keys to increasing energy efficiency, and to the cost-effective expansion of the use of renewables.

Policy targets will only be reached, if climate protection targets are pursued as top priorities, and political solutions are found for overcoming existing barriers. The German government has announced an additional program for the end of 2014 to still reach its medium-term energy and climate mitigation targets for 2020. In the light of recent efforts in the USA to reduce GHG emission substantially and some signals from China that it may be willing to support a global climate agreement in Paris in 2015, this is not impossible, but far from easy with regard to the Reference Forecast.

\section{References}

Ablert, G./Distelkamp, M./Lutz, C./Meyer, B./Mönnig, A./Wolter, M.I. (2009): Das IAB/INFORGEModell, in: Schnur, P./Zika, G. (Eds.): Das IAB/INFORGE-Modell. Ein sektorales makroökonometrisches Projektions- und Simulationsmodell zur Vorausschätzung des längerfristigen Arbeitskräftebedarfs, IAB-Bibliothek 318, Nürnberg, pp. 15-175.

$B M U$ (2012): Langfristszenarien und Strategien für den Ausbau erneuerbarer Energien in Deutschland unter Berücksichtigung der Entwicklung in Europa und global.

European Commission (2013): EU Energy, Transport and GHG Emissions Trends to 2050, Reference Scenario 2013. Under http://ec.europa.eu/energy/observatory/trends_2030/doc/trends_to_20 50_update_2013.pdf (accessed 17.2.2014).

ExxonMobil (2012): Energieprognose 2012-2040, Schwerpunkt: Erdgas - Brücken- oder Basisenergie?

IEA (2012): International Energy Agency. World Energy Outlook 2012, Paris.

Lehr, U./Lutz, C./Edler, D. (2012): Green jobs? Economic impacts of renewable energy in Germany, in: Energy Policy, Vol. 47, pp. 358-364.

Lindenberger, D./Lutz, C./Schlesinger, M. (2010): Szenarien für ein Energiekonzept der Bundesregierungin: Energiewirtschaftliche Tagesfragen, Vol. 60, pp. 32-35.

Lutz, C. (2011): Energy scenarios for Germany: Simulations with the model Panta Rhei. In: D. Mullins, J. Viljoen \& H. Leeuwner (eds.): Interindustry based analysis of macroeconomic fore- 
casting. Proceedings of the 19th INFORUM World Conference. STN Printers, Pretoria, South Africa, pp. 1-22.

Maier, T./Mönnig, A./Zika, G. (2014): Labour Demand by Industrial Sector, Occupational Field and Qualification until 2025 - Model Calculations using the IAB/INFORGE Model. Economic Systems Research, (forthcoming).

Meyer, B./Meyer, M./Distelkamp M. (2012): Modeling Green Growth and Resource Efficiency: New Results, in: Mineral Economics, Vol. 24, pp. 145-154.

Nagl, S./Fürsch, M./Paulus, M./Richter, J./Trüby, J./Lindenberger, D. (2011): Energy Policy Scenarios to Reach Challenging Climate Protection Targets in the German Electricity Sector until 2050, in: Utilities Policy, Vol. 19, pp. 185-192.

Prognos/EWI/GWS (2010): Energieszenarien 2010. Studie im Auftrag des Bundesministeriums für Wirtschaft und Technologie, Basel, Köln, Osnabrück.

Prognos/EWI/GWS (2014): Entwicklung der Energiemärkte - Energiereferenzprognose. Studie im Auftrag des Bundesministeriums für Wirtschaft und Technologie, Basel, Köln, Osnabrück.

Richter, J. (2011): DIMENSION - A Dispatch and Investment Model for European Electricity Markets. EWI Working Paper No. 11/03.

SRU (2010): Sachverständigenrat für Umweltfragen: 100 \% erneuerbare Stromversorgung bis 2050: klimaverträglich, sicher, bezahlbar, Stellungnahme, Berlin.

UBA (2013): Umweltbundesamt. Politikszenarien für den Klimaschutz VI. Treibhausgas-Emissionsszenarien bis zum Jahr 2030. In: Climate Change 04/2013, Dessau-Rosslau. 
Christian Lutz, Dr., managing director of GWS mbH.

Address: Gesellschaft für Wirtschaftliche Strukturforschung mbH, Heinrichstr. 30, D-49078 Osnabrück, Germany, Phone: +49(0)541/40933-120, Fax: +49(0)541/40933-110, E-Mail: lutz@gws-os.com

Dietmar Lindenberger, director of applied research and member of the management board of the Institute of Energy Economics at the University of Cologne (EWI), lecturer at the University of Cologne.

Address: Institute of Energy Economics at the University of Cologne, Vogelsanger Str. 321, D-50827 Köln, Germany, Phone: +49(0)221/27729-108, Fax: 49(0)221/27729-400, E-Mail: Dietmar.Lindenberger@uni-koeln.de

Christian Tode, research associate and doctoral candidate at the Institute of Energy Economics at the University of Cologne (EWI).

Address: Institute of Energy Economics at the University of Cologne, Vogelsanger Str. 321, D-50827 Köln, Germany, Phone: +49(0)221/27729-223, Fax: 49(0)221/27729-400, E-Mail: Christian.Tode@ewi.uni-koeln.de

Michael Schlesinger, director of the division economy, energy, infrastructure.

Address: Prognos AG, Henric Petri-Str. 9,CH-4010 Basel, Switzerland, Phone: +4161/3273-385, Fax: +4161/3273-300, E-Mail: michael.schlesinger@prognos.com 